\title{
Psychoanalytic Aspects of Assisted Reproductive Technology
}

\author{
Geon Ho Bahn \\ Department of Psychiatry, Kyung Hee University School of Medicine, Seoul, Korea
}

\section{보조생식기술의 정신분석적 측면}

반 건 호

경희대학교 의학전문대학원 정신건강의학교실

저 자: Mali Mann

출판사: Karnac Books

출간연도: 2014(ISBN: 978-1-78049-196-7)

난임이란 남녀가 임신을 원하는 상태에서 일 년 이상 임 신에 성공하지 못하는 경우를 말한다. 우리나라의 2015년 난임률은 세 쌍 중 한 쌍으로 매우 높다. 정부에서는 출산율 장려 차원에서 2017년부터 난임부부 시술비 지원을 시작하 였다. 난임 또는 불임 해결을 위한 방법 중 하나가 보조생식 기술(assisted reproductive technology, ART)이다, 시험관수 정(in-vitro fertilization), 난자세포내 정자주입(intra-cytoplasmic sperm injection), 냉동보관(cryopreservation), 자궁 내착상(intra-uterine insemination) 등이 포함된다. 우리나 라는 2012년에 이미 3만 건 이상의 ART가 시행되었고, 성공 률은 $30 \%$ 가 넘는다. 성공하는 부부는 물론 실패하는 부부들 이 공통적으로 겪는 문제가 불안과 우울이지만, 이러한 문제 를 다뤼 주어야 한다는 의식도 충분치 않고, 전문적으로 다 루는 기관 역시 충분치 않을 것이다. 소아정신과의사로서 부 딪히는 문제는 ART로 출생한 아이들의 정서와 인지발달에 관한 문제이다. 특히 ART 특성상 쌍생아 출생 빈도가 높다

Address for correspondence: Geon Ho Bahn, MD

Department of Psychiatry, Kyung Hee University School of Medicine, 23 Kyungheedae-ro, Dongdaemun-gu, Seoul 02447, Korea

Tel: +82-2-958-8556, Fax: +82-2-957-1997

E-mail: mompeian@khu.ac.kr

This is an Open Access article distributed under the terms of the Creative Commons Attribution Non-Commercial License (http://creativecommons.org/licenses/by-nc/4.0) which permits unrestricted non-commercial use, distribution, and reproduction in any medium, provided the original work is properly cited.
보니 육아의 어려움도 배가 된다. ART로 탄생한 최초 사례 는 1978년 루이지 브라운이다. 이후 40여 년이 흘렀고, ART 를 시도하는 부부와 그들 사이에 태어난 아기들이 늘고 있 다. 이들에게 생길 수 있는 정신의학적 문제와 이를 다룰 수 있는 기법에 대한 관심이 이번에 소개하는 책을 열게 만들었 다. 어려운 이론 전개보다는 독자들의 접근성과 실제 임상 현장에서 사용하기 수월하도록 각 장마다 실제 분석 사례를 제공하였다.

이 책은 샌프란시스코 정신분석센터의 정신분석가들이 주축이 되어 저술하였다. 책임저자인 Mali Mann은 샌프란 시스코 정신분석센터에서 지도감독 분석가로 활동하고 있 다. 소아청소년 분석에 관심을 갖고 있으며, 고아원과 학교 체제에 정신분석 접목을 위해 노력하고 있으며, 미국생식의 학회(American Society of Reproductive Medicine) 회원이 기도 하다. 1장은 Mali Mann이 저술하였으며, 체외수정 시 도와 실패에 대해 반복강박(repetition compulsion) 측면에 서 이해를 시도한다. '설명되지 않는 불임'의 경우, 정신역동 상 어린 시절 어머니와의 외상적 또는 불만족스런 기억과 관련되었을 가능성이 있으며, 두 명의 정신분석 사례를 통해 이를 증명하고자 하였다. 분석을 통해 자신들의 문제를 깨닫 고 임신을 시도하지만 건강한 가임기가 지나서 임신이 어려 워지고 인공임신을 시도하게 된다.

2장의 저자는 Diane Ehrensaft로 임상심리학자이며 미국 캘리포니아 오크랜드 샌프란시스코 "Child and Adolescent Center' 창립 회원이자 정신건강 부서 책임자이다. 위탁돌봄 기관의 아동과 젊은이들의 정서문제를 다루기 위해 장기 정 신치료를 제공하는 국가 차원의 프로그램을 수행하고 있다. 이번 장에서는 엄마, 아빠, 아기, 정자 및 난자 제공자, 대리모 
의 가족복합체를 외디푸스 순환고리 측면에서 설명한다. $\mathrm{ART}$ 를 위해 필요한 정자와 난자를 누가 제공할 것인가는 법적으로나 정서적으로나 매우 복잡한 결과를 유발할 수 있 다. 예를 들어, 어머니의 조카(Jessica)에게서 난자를 제공받 아 태어난 아이(Sasha)는 나중에 이 사실을 알게 되자 "Jessica가 내 엄마야?”라고 물었다. Jessica가 결혼하여 아기(Fiona)를 낳자 Sasha는 이런 질문을 한다. "Fiiona가 내 동생이 야?” 특히 동성애자 부부가 ART를 통해 자녀를 갖게 되는 경우, 아이는 혼란스럽다. 왜냐하면 일반 가정과 달리 아빠 가 두 명(게이 부부)이거나 엄마가 두 명(레즈비언 부부)이기 때문이다.

3장은 Terese Schulman이 저술하였고, 그녀는 미국정신 분석학회 회원이자 정신분석가이며, 샌프란시스코 정신분석 센터의 일원이다. 개인사무실은 캘리포니아 오크랜드에 있 다. 여성발달 및 보조생식기술에 관심이 있다. 3장에서는 ART와 모성(motherhood)과 관련된 불안을 정신분석적으 로 어떻게 접근할 것인가에 대하여 제시한다. 임신 중 여성 은 외디푸스기 이전의 어머니와의 동일시를 재경험한다. 어 머니와의 관계가 만족스럽지 못하였거나 어머니에게서 외 상을 받은 경우, 임신을 통해 어머니와의 동일시 경험으로 회귀하는 것은 위협적일 수 있고, 원치 않는 감정이다. 이러 한 양가적 감정 때문에 임신을 기피하기도 한다. 이러한 불 안을 극복하더라도 적절한 가임기가 지나면 원치 않는 ART 를 시도해야 하기도 한다. 정신분석가 또는 정신과 전문의들 이 이러한 특수한 분야의 문제에 대해 대비하지 않으면 이러 한 사례를 만날 때 발생하는 전이/역전이를 다루기 어렵다.

4장은 Mali Mann과 Andrea Mann이 저술하였다. Andrea 는 매우 다양하고 독특한 이력의 정신과의사이다. 캠브리지 대학에서 역학 전공으로 석사학위를 마치고 의학전문대학원 에 진학하였다. 시카고 대학에서 정신과 전공의 과정을 마쳤 고, 맥린센터에서 임상의학윤리 과정을 수료하였다. 이번 장 에서는 $\mathrm{ART}$ 를 시행하기 위해 필요한 정자 및 난자 제공자 에 대한 내용을 다루고 있으며, 제공자가 누구인가에 따라 발생할 수 있는 부모로서의 정체성 형성에 대하여 다륐다. 남성에게 불임의 책임이 있다면 자신의 남성성에 대한 실패 로 경험될 수 있다. 여성의 경우도 마찬가지이다. 인공임신 을 통해 이를 극복하려 하지만 종족 보존 본능 및 창조성의 정체성에 대한 상실감을 극복하는 것은 쉽지 않다. 정자나 난자를 공식 기관에서 제공받기도 하지만, 형제자매나 친척 들의 도움을 받는 경우도 적지 않다. 이 경우 부모로서의 정 체성이 해결해야 할 과제가 된다. 예를 들어 여동생의 난자 를 제공받아 딸을 출산한 사례에서 태어난 딸이 자신의 여 동생(이모, 난자 제공자)에게 더 호감을 갖는 것 같고, 이모
도 자기 딸에게 호감을 보일 때 이 어머니는 자기 여동생에 대한 경쟁심과 열등감을 해결해야 한다.

5장에서는 불임, 외상, 그리고 ART에 대하여 정신분석적 시각으로 조망하였다. 저자인 Monisha Nayar-Akhtar는 미 시간 정신분석연구소에서 수련하였고, 필라델피아 정신분 석센터의 지도감독 분석가이며 펜실베이니아 주 Admore에 서 일하고 있다. 특히 외상 관련 분야의 정신분석에 관심이 있다. 보조생식기술은 복잡하고, 어렵고, 경제적으로 소모적 이며, 오랜 시간이 필요한 과정이다. 시간이 걸릴수록 여성은 자신이 당연히 할 수 있고 해야 하는 일에 실패했다는 느낌이 커질 것이고, 남성 역시 마찬가지이다. ART를 시행함에 따 른 윤리적 딜레마 역시 복합적으로 작용한다. 이러한 문제들 을 정신분석적으로 어떻게 다루고 해결해 나갈 것인지에 대 하여 고찰하였다.

6장은 흥미롭게 전개된다. 저자인 Katherine MacVicar 역 시 샌프란시스코 정신분석센터의 지도 분석가이며, 주로 영 국계 Kleinian 이론을 원시적 마음 상태 분석에 적용하는 작 업을 하였다. 동 센터의 회장과 교육위원회 의장을 지냈으 며, 지난 20여 년간 캘리포니아 'East Bay'에서 정신분석 관 련 영화 토론 모임에 관여하였다. 이번 장 역시 영화 'The kids are all right'를 통해 보조생식기술의 새로운 측면을 제 공한다. 이 영화는 ART로 자녀를 얻은 레즈비언 부부 가족 의 어려움을 코미디 방식으로 다맀다. 이 부부는 동일한 인 물의 정자를 기증받아 인공수정으로 딸과 아들을 출산하였 고, 따라서 아이들은 생물학적 아버지가 같기 때문에 남매 관계이다. 생물학적 아버지가 가족 구성원 안에 없기 때문에 두 명의 어머니만 있으며, 아버지 역할은 직장을 다니는 Nic 이 담당하며, 집안일은 Juels이 담당한다. 딸 Joni는 18 세가 되는 해, 정자은행 기록을 통해 생물학적 아버지 Paul을 만 난다. Paul의 등장으로 레즈비언 부부와 두 자녀는 미묘한 감정과 긴장감을 경험한다. $\mathrm{Nic}$ 은 $\mathrm{Paul}$ 에게 경쟁심을 느끼 고, Jules은 이성관계를 맺기도 한다. 이름마저도 남성스러 운 Laser가 Clay라는 나쁜 친구와 가까워지는 것을 레즈비 언 부모는 제대로 해결하지 못하지만, Paul은 Laser가 Clay 의 나쁜 점을 제대로 볼 수 있도록 도와주고 헤어지게 한다. 하지만 Nic과 Jules은 이러한 갈등과 긴장을 잘 견뎌 내면서 부모로서의 위치를 잘 유지할 수 있었다. 영화 제목처럼 부 모 사이가 좋다는 것을 느낀다면 아이들도 괜찮을 것이다. 이 영화는 인공수정을 통해 태어난 아이들의 삶에서 만날 수 있는 여러 가지 중요한 심리적 주제들을 다루고 있으며, 특히 레즈비언 부부 가족도 특별한 가족이 아닌 정상적 가 족 구성과 역동을 가질 수 있음을 보여준다.

ART는 생물학적 원인으로 인한 불임 부부에게는 절대 놓 
치고 싶지 않은 희망의 동아줄이다. 정신역동상 불임이 지속 되었다가 시간이 지나면서 또는 (정신분석적) 정신치료를 통해 이를 극복하더라도 나이 때문에 임신이 어려워지는 경 우에도 ART를 시도할 수 있다. ART가 이들에게 희망을 줄 수 있는 소중한 기법이지만, 건강하고 성공적인 출산을 이루 기 위해서 부부는 불안, 분노, 죄책감, 상실감 등을 극복해야 한다. ART로 태어난 아이들의 정체성 혼란이나 부부 각자 가 다뤄야 할 정서문제도 다양하게 나타난다. 많은 정신분석 논문에서 불임 치료와 관련된 내용을 다뤘으나, ART를 선
택한 환자들의 마음과 자녀 양육에 미치는 영향을 다룬 연 구는 많지 않다. ART를 받는 부부나 시술하는 산부인과 의 사들도 이러한 문제에 대한 의식이 충분치 않을 것이다. 정 신분석가 또는 정신과의사들은 보조생식의학 관련 분야 전 문가들과 교류와 협력을 통해 이러한 갈등과 고민을 해결해 줄 수 있도록 노력해야 할 것이다.

이 책을 함께 읽었던 경희대학교병원 정신건강의학과 전 공의들에게 고마운 마음을 전하며, 정신건강의학과는 물론 산부인과 및 보조생식의학 관련자들에게도 일독을 권한다. 